\title{
Methods of Teaching EST from the Stylistic Perspective and the Content of EST Reading
}

\author{
Junfeng Huang \\ Foreign Language School, Changchun University of Science and Technology, Changchun, China \\ Email: huang-809@hotmail.com \\ Jing Chen \\ Jilin Huaqiao Foreign Languages Institute, Changchun, China \\ Email: chenjing.m@163.com
}

\begin{abstract}
To meet the requirements of the present job-hunting market, Huaqiao Foreign Languages Institute has set up English for Science and Technology (EST) courses for the senior students majored in English, which consist of Reading of EST and EST Translation. This article, mainly dealing with EST reading, discusses some tentative teaching methods from the perspective of stylistic features and EST reading content in order to cultivate the students with problem-solving capabilities.
\end{abstract}

Index Terms - EST reading, stylistic features, content-based instruction(CBI)

\section{INTRODUCTION}

In recent years, many foreign language schools have already opened or are planning to offer the course of English for Science and Technology (EST) but with no much effectiveness, subject to the limitation of teaching materials, faculties and other unfavorable factors. English major students will lose the chances to play their roles if they cannot find the right way to master both the foreign language and scientific knowledge. Therefore, how to cultivate undergraduates with applied competence becomes an upmost topic for every course reformation in Jilin Huaqiao Foreign Languages Institute (HUAWAI).

EST course is a senior optional course for students with interest or higher expectations in their future career, so the teacher is greatly mobilized. EST teaching consists of reading of EST and EST translation, which are closely related. EST course not only focuses on some scientific vocabularies and stylistic knowledge related to EST, but also emphasizes the content of EST. This paper only puts emphasis on the teaching methodology of EST reading. Practical teaching methods can improve the students' self-learning ability, which determines their competitive capacity and developing capacity. The article puts forward some ideas about the teaching method of EST reading from the perspective of stylistic features and content.

\section{Stylistic Features of EST}

EST is indeed a large variety, which contains many different aspects such as the English of medicine, the English of biology, the English of mathematics, the English of physics, etc. It is widely applied in the description or explanation of natural phenomena, academic thesis, research papers, scientific works and experimental reports. Above all, EST is a variety of English, dealing with the theories and applications of science and technology. We are trying to adopt the teaching method of EST reading from the perspective of stylistics, which is based on content and aims to help the students have a better understanding of EST, a new kind of domain for most of them.

EST is an applied English style with its own special words, grammatical structures and expressions, which shows its characteristics of accuracy, objectivity and conciseness. Therefore, EST can be well comprehended by analogy from the perspective of stylistic features.

\section{A. In Vocabulary}

There are three kinds of words in EST, namely technical words, semi/sub-technical words and non-technical words. The technical words refer to the words that can exactly explain definite concepts in a specific field of science and technology. They are used to register and express phenomena, processes, characteristics, relationships, conditions and quantities, etc. in the given field, for example laser, spaceship, isotope. Technical words account for $21 \%$ of EST vocabulary. One term only has one meaning, so students have no difficulty in reading and comprehending them with the help of specific reference books. Semi-technical words are also called sub-technical words, whose use is not only confined to scientific and technological contexts. Some of them are formed from Latin or Greek roots and they have also been taken from everyday language and given precise definitions for scientific use. Therefore, the meanings of these words in their technical use are likely different from their non-technical meanings, such as power, module, force, 
mass, etc. Semi-technical words take up 70\% of EST vocabulary, each having a different meaning in a different field, which causes difficulty for language studying students. So it is necessary for teachers to spend more time and efforts on semi-technical words. Non-technical words, on the one hand, are understood to be words and expressions which are seldom found outside scientific English, for example convert (change), prior to (before), simultaneously (at the same time), etc. They seem to avoid the ambiguity or imprecision of more commonly used words with the apparent meanings. According to statistic analysis, the non-technical words only account for $9 \%$.

\section{B. In Grammar}

The EST writing is accurate, clear, rigorous, objective and logical, so it has the following features in grammar.

In EST writings complex sentences are often simplified into simple sentences by changing verbs, adjectives or other parts of speech into nouns that is nominalization structures. Nominalization is more formal than its counterpart, therefore more frequently occurring in EST. In this kind of structure, objective facts are stressed to make the expression of concept more accurate. For example,

(1) Sawing of wafers results in loss of silicon as sawdust.

(2) Among the improvements were automation and change in the method of sawing boule into wafers.

(3) Television is the transmission and reception of images of moving objects by radio waves.

In EST non-finite phrases take the place of attributive clauses or adverbial clauses to make the expressions concise and its structure compact. For example,

(4) Astropower straddles the line between bulk and film material, growing a relatively thick film of polycrystalline silicon on a low cost subtract.

(5) Consisting of a cylindrical cathode surrounded by a tube-shaped anode, this source works in conjunction with an electron beam evaporator, with the plasma assisting the deposition process.

In EST writing, passive voice is used more frequently by the scientists. Though passive voice sentences are frequently used in EST, there are also some active voice sentences to replace passive voice sentences, such as (1)active voice sentence showing passive voice meaning; (2)sentence with intransitive verb as predicative indicating passive voice meaning; (3)active voice form of gerund used as object showing passive voice meaning. For example,

(1)This article explores the measurement for weak magnetic field present in the human body.

(2)Aluminum machines faster than other metals.

(3)These instruments need very careful handling.

Besides these sentences, stative sentences also belong to the active voice sentences. For example,

The system is composed of an undersea acoustic beacon.

The sensor is housed in a support assembly when the gear is down locked.

Using active voice sentences in EST is becoming a trend. It makes the expression concise and vivid with dynamic sense.

At present, many universities in China have established some professional EST courses, and some others are preparing for setting up similar courses. Though EST courses have been carried out for a rather long time, the result is not quite satisfactory. Students have not mastered the skills required as the universities had expected, although they have attended the EST courses. It becomes crucial for the teachers to carry out the teaching reforms so as to find the appropriate teaching approaches. The traditional EST teaching put too much emphasis on the EST vocabulary, words translation and stylistic explanation, ignoring the content of true technical articles. Thus, it is significant to find an appropriate teaching method to focus on both the content and the language.

\section{EST READING BASED ON CONTENT}

The trend of instruction which integrates language and content has been a popular phenomenon in the language field since the early 1980s. According to Crandall and Tucker's definition, content is clearly academic subject matter. While Genesee (1994) suggests that content "...need not be academic; it can include any topic, theme or non-language issue of interest or importance to the learners" (p. 3). Met (1999) has proposed that “... 'content' in content-based programs represents material that is cognitively engaging and demanding for the learner, and is material that extends beyond the target language or target culture" (p. 150). Although content is used with a variety of different meanings in language teaching, it most frequently refers to substance or subject matter that we learn or communicate through language rather than the language used to convey it.

The term CBI is commonly used to describe approaches to integrating language and content instruction, but it is not always used in the same way. For example, Crandall and Tucker (1990) define it as “...an approach to language instruction that integrates the presentation of topics or tasks from subject matter classes within the context of teaching a second or foreign language" (p. 187). Curtain and Pesola (1994) use the term in a more restricted way, limiting it to only those "...curriculum concepts being taught through the foreign language...appropriate to the grade level of the students” (p. 35). Krueger and Ryan (1993) distinguish between content-based and form-based instruction, and note that the term discipline-based more appropriately captures the integration of language learning with different academic disciplines and contents. In general, CBI refers to an approach to second language teaching in which teaching is organized around the content or information that students will acquire, rather than around a linguistic or other type of 
syllabus.

\section{A. The Rules of CBI}

In carrying out $\mathrm{CBI}$ there are several rules that we must obey. Firstly, the teaching decision is based on the teaching content. From the perspective of curriculum design of teaching writing, the traditional teaching method usually follows the order ranging from the easy to the difficult. For example, the present continuous tense is usually placed at the elementary stage, for it is the very easiest for learners to grasp. Whereas CBI subverts the choice and order employed in traditional teaching method, it completely gives up the language points as the threshold and gives priority to the content in teaching.

Secondly, it is filled with integration of the four basic learning skills: listening, speaking, reading and writing skills. Previous teaching method often employs one or two of specific skills in the language learning. But CBI tries to integrate the four basic skills, which includes the grammar and vocabulary items in a teaching program. The order of the four basic skills is not fixed or immutable; on the contrary, it can start from any skills. This rule, the extension of the first one, is the concrete reflection on the choice or sequence of teaching items decided by content.

Thirdly, students are required to actively participate in every level of teaching. Since the communicative approach began to prevail in teaching methods, the center of classroom teaching has been turned to the learners. Learning by doing has become the basic principle of language teaching. Task-based teaching is one branch of communicative approach, which emphasizes that students must gain knowledge through different tasks. CBI is also a branch of communicative approach, which emphasizes studying and participating in any activities actively. In CBI classroom, students and teacher play a variety of roles in teaching.

Fourthly, the selection of content must be relevant to the students' interests and learning style. The choice of content in CBI is usually in parallel with the teaching subjects. Thus, in schools, foreign language teaching content can come from other subjects such as history or science.

Fifthly, the combination of the authentic text and applied task must be followed. The hardcore of CBI is the authenticity, which gives the priority to authentic text and real task. Authenticity is not limited to the content of teaching materials such as a ballad or a story, cartoon pictures can be used as practical teaching assistant in language learning too. Tasks must be connected with certain context and reflect the actual situation of real world.

Lastly, CBI emphasizes the study of language structure. It will expose students to authentic language input to make them gain the ability in language for communication. The sources of information in CBI can be all kinds of media related to content and simple input can not lead to successful language learning. Towards the language structure in authentic texts, we must take a direct approach to raise awareness of learning.

For us CBI means understanding the content of a text rather than remembering some technical terms, which can help the students know better about principles, techniques or some knowledge. Although language learning students and science students vary in some aspects, more attention to the way of thinking of scientific researchers is beneficial for students to foster comprehensive abilities. We tried to do some empirical research on whether CBI can be effectively applied into EST teaching. The research aims at the application of CBI in EST teaching. The final goal of the research is to prove that $\mathrm{CBI}$ is an effective teaching approach for EST reading in China.

\section{B. Models of CBI}

The rules of CBI can be applied to the design of courses for learners at any level of language learning. Generally speaking, CBI can be classified into the following models.

1. Theme-based Language Instruction

Theme-based Language Instruction refers to the syllabus which is designed due to different themes or topics such as environment protection, legal rights (Brinton et al, 1989). The language syllabus is organized according to the theme. In the process of a course, the topic must be introduced at the beginning, and then other classroom activities are followed. Such as guided discussion, audio or video materials, listening comprehension and written assignment, during which language analysis and practice can be carried out at the same time. Under this model, the content is not only the basis of the course design, but also the basis of language analysis and practice. The disadvantages of the model lied in that the teachers must concentrate all their attention on the research of the teaching materials, while the learners can review the vocabulary and concept in a circling way so as to improve their expressing ability. This mode is applied in a broad way, because it can be used in different teaching environments. This model put emphasis on learning strategies, concepts, tasks and skills.

\section{Sheltered Content Instruction}

Sheltered Content Instruction refers to content courses instructed in the second language by a content field expert, to a team of ESL learners who have been gathered to accomplish their desire of learning the course. The experts are believed to explain the content in a comprehensible way using the language and task at a proper level of difficulty. Characteristically, the instructors will select the appropriate content according to ESL learners' capacity. In the process of the course, the instructors will make their course easier if they find the content is difficult for the students to accept.

3. Adjunct Language Instruction

Adjunct Language Instruction means that students are required to participate in two connected courses, that is, a content course and a language course. Both courses are based on the same content and complement each other in terms 
of mutually coordinated assignments. This model requires a large amount of coordination to ensure that the two curricula are interlocking and this may require modification to both courses (Shih, 1986).

An adjunct course focusing on the science takes both ESL teachers and science teachers into consideration in the aspect of the course, which focuses on preparing students to make the transition to learning science through the English. The adjunct course focused on the following aspects: a) understanding specialized science terminologies and concepts; b) report writing skills; c) grammar for science; d) note-taking skills.

This model requires students master the professional knowledge through the language. It should be carried out by both content teachers and language teachers. The language teachers take the responsibility to make the students familiar with the professional knowledge by reading some professional books and listening to the professional teachers' classes. The schedule of the course requires the cooperation between professional teachers and language teachers.

There are some advantages and disadvantages for the three models. Theme-based Language Instruction can be applied under the environment of a variety of courses. Therefore, it can be applied to second language learners. The sheltered model is only suitable for the second language learners at a higher level; whereas, the adjunct model is only applied to the second language learners from an ordinary level to a professional level. In short, they are suitable for second language learners at different levels or teaching environments. If necessary, we may combine the features of all three models and establish a new teaching model.

\section{CRITICAl Thinking OVER EST READING}

Content-based instruction, short for CBI, is the combination of a specific topic or academic content and language teaching, which enables students to get access to information through a second language in the process of developing language skills. Currently, the linguists and scholars from the United Kingdom, the United States and other countries widely employ CBI in language teaching, proving it to be an effective teaching method of subject integration. The emergence of CBI shed a bright light to the EST teaching. Scholars both at home and abroad did some researches on how CBI can be effectively applied in teaching and they drew the conclusion that CBI is an effective way for EST teaching.

In the process of application of CBI in EST reading, we proposed that the EST teaching should be dealt with from three points of integration: the integration of teaching and theme, the integration of theme and task, and the integration of task and goal. As we know, classroom teaching must be closely connected with the theme of the teaching content. Only the theme is centered can we enhance classroom teaching effectiveness and the interaction between teachers and students truly take place. At the first point, we switch students' attention to the real theme content when they are reading EST at school. At the second point, theme and task are combined to cultivate the four basic skills. This requires teachers not only to illustrate the content, but also to arrange some practical task such as reading, writing and translating practice for students to complete. At the third point, the combination of task and goal enables students to apply what they have learned in EST class to objective reality, or their learning skills. In addition, after class activities also play a significant role in implementing CBI. The teachers can provide students with relevant reading materials including books, magazines and video CDs associated with the themes in order to develop students' interests and help students understand reading content in learning EST.

\section{A. Specialized Knowledge Explanation for Accurate Understanding}

Since CBI is a teaching approach which integrates the language and the content, the teacher just concentrated on the teaching of the text itself in the research. The textbook that the students are reading in HUAWAI is called 'Practical EST Reading' which has been newly published based on content. All the texts selected in the book are in close connection with the development of EST. This reading book includes 12 units, covering knowledge of some advanced technology such as automotive night vision, autonomous cow-milking robot, solar energy, laser etc. The textbook was completely written on the basis of technical content by EST teachers in Changchun University of Science and Technology (CUST), and the EST course has been employed by CUST for several years. We also chose the book as our major textbook used in EST class.

A lot of professional knowledge is involved in the reading material. Take the text of 'Solar Cells' for instance, by means of PPT specifically made, students can learn the structure of a solar-cell module, and understand the growth of polycrystalline as a starting material for cells as well as thin-film fabrication for low-cost cells. All key words relating to the technical domain are picked up as the teaching focuses in class. For example,

Part of the motivation for thin-film silicon work is its ability to use layers of silicon only a few microns thick, rather than the freestanding silicon wafers that are hundreds of micron thick. (The freestanding silicon wafers refer to the bulk ones, using thin-film silicon can save a lot of materials for fabrication of solar cells).

The manufacturing plant uses a roll-to-roll continuous deposition process that deposits nine layers of film on a $35 \mathrm{~cm}$ wide and $762 \mathrm{~m}$ long substrate. (Film system design is mentioned here, the film consists of nine layers).

In order to create a harmonious atmosphere or to improve the classroom efficiency, the classroom teaching must be strictly connected with the theme of every unit. In this way students can concentrate their energies on key points of teaching content.

\section{B. Arousing Students' Interest from a Real Case}


To promote students' learning motivation, or to reduce students' fear of science, the teacher should introduce some relevant information to EST texts through a series of lectures at the beginning of class. Take the text of 'Solar Cell' for instance, solar energy can be applied in the following four fields: photothermy, solar generated power, photochemical reaction and photo-biologic application. Mr. Huang Ming, the President of Huang Ming Group Company and Vice-chairman of International Solar Energy Society, puts forward G (Green) Energy Alternative Strategy. According to the plan, solar power will take the place of 50\% of the traditional energy. Mr. Huang Ming has built up a "solar city" in Dezhou City, Shandong Province in China, where all energy used by the city is from solar energy. Obviously, solar cells have a greater potential market. Students good at English and with a good knowledge of the solar field will play an important role in future career. The introduction to a real case stimulates students' interest and increases their confidence, so students will study the EST vigorously and persistently.

\section{Teaching on Demand of Market}

The teaching goal of EST is to further improve the students' reading comprehension ability and comprehensive analyzing ability through EST learning. Students are required to read the authentic language materials, expand EST vision, and get familiar with the writing code of EST style. EST has been taught for many years in some colleges and universities without any unified textbook, and it is impossible to have any common textbook in the future. The English departments in some universities of science and technology take their professional edges as the teaching content, while the EST reading textbooks adopted by comprehensive universities are mainly derived from some well-known publishers. In HUAWAI, EST course is offered to cultivate capable graduates in order to meet the need of job-hunting market, or specifically speaking, to train them to perform well in small or medium sized enterprises with foreign language.

As early as in the millennium year of 2000, scientists predicted that one of the most vigorous industries in the new era is in the line of photoelectronics, which will change our lives in ways beyond our imagination. According to statistics, the number of optoelectronic enterprises in China, big or small, has grown from 415 in 2008 to over 7000 with a significant portion of export. Therefore, there is a great need for talents in the field.

Photoelectronic technology ranges widely, and our teaching content focuses on the most prosperous aspects such as robots, solar cells, laser application, optical coating and light-emitting diodes etc. to help students to learn some essential knowledge about science and technology for employment and professional development, or to foster students' ability of science expression.

\section{Fostering Students' Creative Thinking}

The article 'Solar Energy' analyzes the factors which influence the cost of solar cells, including the raw material, interconnections and encapsulation. The silicon wafers represent about a third of the cost of a module. So it is essential to lower cost from material. Scientists tend to use layers of silicon only a few microns thick, rather than the freestanding silicon wafers that are hundreds on microns thick. Semiconductor-grade silicon offers lower cost and does not degrade. With thin-film silicon, aluminum frame is not necessarily used. As for interconnection, research is underway to develop a cell geometry that would place all the contacts on one side- this would simplify interconnection, which greatly reduces the cost. To prolong the lifetime of a module is the best way to save cost. The introduction to photovoltaic knowledge on how to lower the cost of solar cells helps students train their logical thinking.

Innovation is actually pretty hard but "not difficult", with the analogy of permutations in mathematics. For a crutch, the most conspicuous parts are "handle" and "tip". New products come out after grouping of a set of things. The analogy is too simple, but it can help students understand creativity better. In the process of teaching, elicitation and reflection would produce interaction between the teacher and students, which finally results in satisfactory effects on teaching and learning.

\section{CONCLUSION}

Recently the new teaching method of EST has been investigated in China. Being double-duty EST teachers, we would never stop learning advanced sciences and technology in order to follow the trends in the teaching of foreign languages. We would hold more extracurricular activities to solve the problem of less classroom activities. Besides PPT made by our teachers, any other kinds of measures are taken for the EST contents. Such as popular science lectures arranged at intervals of a semester and new tech exhibitions attended are very helpful for the students to deepen their understanding of sciences and cultivate their problem-solving capacities independently. Actually EST teaching innovation is a permanent subject for our teaching staff, which needs time and efforts. We are eager to communicate with teachers who are dealing with the same problems.

\section{REFERENCES}

[1] Brinton, D., M. Snow \& M. Wesche. (1989). Content-Based Language Instruction. New York: Newbury House.

[2] Brown, H. Douglas. (1994). Principles of Language Learning and Teaching. Englewood Cliffs, NJ: Prentice Hall.

[3] Crandall, J. (1993). Content-centered Learning in the United States. NY: Cambridge University Press.

[4] Crandall, J. \& G. Richard Tucker. (1990). Content-based Instruction in Second and Foreign Languages. Newburry Park, CA: Sage. 
[5] Curtain, H.A. \& Carol Ann Pesola. (1994). Languages and Children: Making the Match. New York: Longman.

[6] Genesee, F. (1994). Integrating Language and Content: Lessons from Immersion. CA: National Center for Research on Cultural Diversity and Second Language Learning.

[7] Huang, Junfeng. (2010). Practical EST Reading. Changchun: Northeast Normal University Press.

[8] Hutchinson, T. \& A. Waters. (1987). English for Specific Purposes: A Learner-centered Approach. Cambridge: Cambridge University Press.

[9] Krueger, M. \& F. Ryan. (1993). Language and Content: Discipline and Content-based Approaches to Language Study. Lexington, MA: DC Health

[10] Met, M. (1991). Learning Language Through Content: Learning Content Through Language. Foreign Language Annals, 4, 281-295.

[11] Shih, M. (1986). Content-based Approaches to Teaching Academic Writing. TESOL Quarterly, 4, 617-648.

[12] Stryker, S. B. \& B. L. Leaver. (1997). Content-based Instruction in Foreign Language Education: Models and Methods. Washington: Georgetown University Press.

[13] Widdowson, H. G. (1999). Aspects of Language Teaching. Shanghai: Foreign Language Education Press.

[14] Xu, Youzhi. (2005). English Stylistics. Beijing: Higher Education Press.

Junfeng Huang was born in Changchun, China in 1971. He received his M.A. degree in English Linguistics, Changchun University of Science and Technology in 2003.

$\mathrm{He}$ is currently an associate professor at Foreign Language School, Changchun University of Science and Technology, Changchun, China. His research interest lies in English teaching and translation.

Jing Chen was born in Xuzhou, China in 1981. She received her M.A. degree in English Linguistics, Changchun University of Science and Technology in 2006.

She is currently a lecturer at Jilin Huaqiao Foreign Languages Institute, Changchun, China. Her research interest lies in Applied Linguistics. 